\title{
A Eficiência das Explorações Leiteiras Micaelenses (Açores)
}

\author{
Bruno Aires da Silva Almeida ${ }^{1}$ e \\ Emiliana Leonilde Dinis Gil Soares da Silva²
}

Resumo: A discussão no âmbito da Política Agrícola Comum marca a atualidade açoriana. Um cenário possível é o decréscimo de apoios, subsídios à quota leiteira, aos produtores açorianos. Para compensar esta quebra de rendimento urge que os produtores leiteiros melhorem a eficiências das suas empresas agrícolas. Este trabalho tem como objetivo conhecer os valores de eficiência e estimar o número de explorações eficientes em S. Miguel, ilha que contribui com $75 \%$ da produção regional. A produção de leite dos Açores representa 30\% da portuguesa. Neste trabalho utilizaram-se 91 explorações micaelenses. Estimam-se a eficiência usando o Deap. Utilizam-se dois modelos de eficiência não paramétrica alternativos: considerando, ou não, os subsídios como output. No Modelo I verificou-se que 7 (7,69\%) explorações são eficientes. O nível de ineficiência técnica é de 0,312, ou seja, pode reduzir-se até $31,2 \%$ dos gastos nos consumos sem penalizar a produção. A eficiência técnica baixa de $68,8 \%$ no Modelo I para $63,7 \%$ no Modelo II, em que apenas $5(5,49 \%)$ explorações são eficientes. Este trabalho caracteriza a estrutura das empresas pecuárias, apresenta a metodologia DEA, os trabalhos mais relevantes nesta área, apresenta e discute os resultados. Finalmente, apresentam-se as considerações finais e a bibliografia.

Palavras-chaves: Açores, "Data Envelopment Analysis", eficiência, leite, modelos.

Abstract: The discussion of the Common Agricultural Policy is ongoing. One possible scenario is the reduction of support of the Azorean farms. To compensate this loss of income, dairy farmers will improve the efficiency of their farms. This paper aims to estimate the efficiency values and the number of efficient farms in S. Miguel Island, which contributes with $75 \%$ of regional production. Milk production in the Azores represents $30 \%$ of the Portuguese. This research was going in $91 \mathrm{~S}$. Miguel farms. The efficiency was estimated using the DEAP. Two models are available: considering whether or not subsidies as output. The Model I showed that 7 (7.69\%) farms are efficient. The level of technical efficiency is

1. Engenheiro Zootécnico, Mestre em Zootecnica. AASM (Associação Agrícola de S. Miguel). E-mail: bruno_almeida45@hotmail.com

2. Professora Auxiliar cm Agregação, Doutora em Economia Agroalimentar. Universidade dos Açores - DCA - CEEAplA. E-mail: emiliana@uac.pt 
0.312, which means, it can be possible to reduce up to $31.2 \%$ of expenditures in consumption without penalizing production. The technical efficiency of 68.8\% in Model I decrease to $63.7 \%$ in Model II, in this study case, 5 (5.49\%) farms are efficient. This study characterizes the structure of the farms, presents the DEA and the most relevant work in this area, and discussion of the results. Finally, there are the concluding remarks and bibliography.

Key-words: Azores, Data Envelopment Analysis, efficiency, milk, models.

Classificação JEL: Q12.

DOI: http://dx.doi.org/10.1590/1234-56781806-94790053s01010

\section{Introdução}

S. Miguel é a maior das ilhas da Região Autónoma dos Açores, quer em população, quer em dimensão. A produção agrícola é uma componente importante no produto interno bruto. A fileira do leite tem o maior impacto na economia dos Açores, embora a fileira da carne, as pescas e o turismo também se apresentem como alternativas de produção. A produção leiteira de vaca e do queijo representam, respetivamente, $28,4 \%$ e $35,0 \%$ da produção do total a nível nacional (INE, 2009).

O objetivo deste trabalho é conhecer a eficiência económica de 91 das explorações micaelenses. Para tal, utiliza-se a análise não paramétrica de eficiência (Data envelopment analysis) e o DEAP Program para calcular a eficiência técnica a rendimentos variáveis e a rendimentos constantes.
Neste trabalho apresenta-se uma caracterização sumária da Região Autónoma dos Açores, uma descrição da metodologia e algumas investigações que recorreram a esta metodologia. Finalmente, apresentam-se os resultados e conclusões.

\section{Fundamentação teórica}

Em 2009, o efetivo bovino nacional era de 1.391 .000 animais, dos quais $(20,0 \%)$ eram vacas leiteiras com idade igual ou superior a dois anos, que tinham parido pelo menos uma vez e cujo leite produzido era principalmente vendido ou autoconsumido pela família do produtor (INE, 2011).

O Quadro 1 mostra-nos que o número de bovinos diminui $2.1 \%$ entre o ano de 1999 e 2009. Neste período de tempo, o número de vacas lei-

Quadro 1. Distribuição do efetivo bovino pelas regiões do país (1999 e 2009) (Unidade: 1000 cabeças)

\begin{tabular}{ccccc}
\hline \multirow{2}{*}{ Regiões } & \multicolumn{2}{c}{1999} & \multicolumn{2}{c}{2009} \\
\cline { 2 - 5 } & Total de Bovinos & Total de Vacas Leiteiras & Total de Bovinos & Total de Vacas Leiteiras \\
\hline Norte & 400 & 133 & 323 & 103 \\
Centro & 210 & 74 & 201 & 39 \\
Lisboa & 161 & 29 & 46 & 21 \\
Alentejo & 393 & 21 & 562 & 21 \\
Algarve & 12 & 1 & 9 & 1 \\
Açores & 240 & 99 & 245 & 92 \\
Madeira & 4 & 1 & 5 & 1 \\
Total & 1421 & 357 & 1391 & 278 \\
\hline
\end{tabular}

Fonte: INE (2000, 2011). 
teiras diminuiu $22 \%$ registando a maior descida na região Centro (Beira Litoral e Beira Interior). O Alentejo é a região que tem maior expressão na produção bovina ( $39 \%$ do efetivo nacional, quase exclusivamente para a produção de carne) Seguem-se as regiões predominantemente leiteiras, do Norte (Entre Douro e Minho) com 18\% e os Açores com $17 \%$, que em conjunto concentram mais de 2/3 do efetivo leiteiro de Portugal.

Em Portugal, em 2009, o efetivo bovino médio por exploração era de 26,7 cabeças. Em anos mais recentes observa-se, que as explorações de bovinos leiteiros convergem para um sistema de estabulação, sendo no Norte mais expressiva. Em Lisboa e no Centro a estabulação é significativa e concentram os sistemas mais intensivos de produção de bovinos de carne e de leite. Pelo contrário, a sua expressão é mínima no Alentejo e nos Açores, pela utilização quase exclusiva de sistemas extensivos nestas duas regiões.

No Quadro 2 observa-se que a produção de leite de vaca entre 1999 e 2009 tem-se mantido constante, não obstante da diminuição gradual nos últimos 10 anos no número do efetivo leiteiro. Isto é, a média de produção por vaca tem aumentado significativamente (em 1999 era de $5.541 \mathrm{~kg}$, e em 2009 era $6.973 \mathrm{~kg}$ aumentando de $21 \%$ ). Verifica-se também um aumento no Teor Butiroso (TB) e no Teor Proteico (TP).

Em 2009 foram recenseadas 13.541 explorações agrícolas, em que S. Miguel tem cerca de metade (42,2\%) do total (SREA, 2011). A fileira do leite regista um enorme impacto na economia dos Açores. Segundo o INE (2009), do total da produção de vaca em Portugal em 2007, os Açores contribuíram com $28,4 \%$, sendo que a produção da ilha de São Miguel contribuiu com 63,7\% do total açoriano. Em São Miguel, nos últimos anos, tem-se observado um aumento dos produtos de valor acrescentado, como o queijo e iogurtes em detrimento dos produtos com menor valorização (leite em pó e da manteiga). Em 2005, a produção de manteiga e do leite em pó atingiu os $24,4 \%$ e os 97,1\% do total nacional (INE, 2009).

Esta nova mudança de política das empresas de transformação deve-se à valorização dos produtos pela diferenciação e criação da "Marca Açores" permitindo, por exemplo, que em 2005 o queijo produzido na RAA já atingisse os 35\% da produção nacional. Existem em Portugal doze queijos com Denominação de Origem Protegida (DOP), sendo que dois são açorianos: o queijo de São Jorge e o queijo do Pico. No caso do queijo de São Jorge a sua produção representa mais de $50 \%$ da produção nacional de queijos DOP, porém, é o produto com menor valor médio de venda por unidade (INE, 2009).

Na União Europeia a produção leiteira é controlada por um sistema de quotas atribuída a cada país membro. Para Portugal foi atribuído, em 2011, uma quota de 2.02 milhões de toneladas (t) (IFAP, 2012) e para os Açores de 548 mil t. Este

Quadro 2. Distribuição da Produção de Leite de Vaca em Portugal (1999-2009) (Unidade: litros (milhares))

\begin{tabular}{ccccc}
\hline Anos & Leite Total & Leite de Vaca & TB (\%) & TP (\%) \\
\hline 1999 & 2.116 .967 & 1.978 .471 & 3.78 & 3.16 \\
2000 & 2.136 .285 & 1.998 .216 & 3.80 & 3.22 \\
2001 & 2.054 .270 & 1.923 .577 & 3.83 & 3.27 \\
2002 & 2.166 .501 & 2.039 .727 & 3.84 & 3.25 \\
2003 & 2.019 .952 & 1.893 .243 & 3.81 & 3.28 \\
2004 & 2.076 .958 & 1.949 .670 & 3.85 & 3.28 \\
2005 & 2.128 .412 & 1.999 .234 & 3.85 & 3.28 \\
2006 & 2.048 .724 & 1.924 .111 & 3.84 & 3.25 \\
2007 & 2.028 .789 & 1.909 .440 & 3.85 & 3.28 \\
2008 & 2.076 .769 & 1.960 .899 & 3.86 & 3.27 \\
2009 & 2.047 .593 & 1.938 .641 & 3.83 & 3.28 \\
\hline
\end{tabular}

Fonte: INE (2000, 2001, 2002, 2003, 2004, 2005, 2006, 2007, 2008, 2009, 2010). 
tipo de sistema é necessário para a sobrevivência económica dos pequenos núcleos leiteiros como é o caso dos Açores. Com a supressão das quotas leiteiras os Açores serão submetidos ao nível concorrencial das grandes potências leiteiras da Europa.

Apesar destas dificuldades, o sector leiteiro açoriano tem pontos fortes, nomeadamente: uma indústria modernizada capaz de inovar e/ou criar novos produtos mais saudáveis e de uso fácil; ter uma fileira leiteira estruturada; os produtos lácteos produzidos na região têm excelente qualidade e com propriedades químicas únicas; possuir dois produtos DOP; uma imagem de um produto "Marca Açores" que está associado à região e à sua qualidade ambiental (Almeida, 2012).

Porém, as ameaças à fileira do leite açoriano nomeadamente o fim das quotas em 2015 irá acrescer o nível concorrencial dos produtos lácteos provocando, possivelmente um abaixamento do preço do leite e, consequentemente uma diminuição da rentabilidade económica das explorações leiteiras com os custos de produção a aumentar anualmente. Acrescendo o fato de serem uma região ultra periférica, os custos de transporte e de logística são maiores e o mercado regional ter menor dimensão (ALMEIDA, 2012).

\section{Estrutura económica das explorações agropecuárias dos Açores}

O produto bruto das explorações agropecuárias dos Açores é constituído na sua maioria na produção de leite e de carne. A venda de leite e de carne representam $61 \%$ do total de receitas, sendo que a venda de leite contribui com $84,1 \%$ e a venda de carne com os restantes $15,9 \%$. A produção de carne é representada como uma atividade complementar e não como uma atividade alternativa (SILVA, 2001). Os subsídios recebidos representam $18 \%$ do total da estrutura do produto agrícola, baixando para $16,9 \%$ na ilha de São Miguel. Nesta mesma ilha e segundo a mesma autora, o valor das receitas do leite e da carne totalizam $65,9 \%$ das receitas $(91,3 \%$ para o leite e $8,7 \%$ para a carne).

Silva (2001) constata que a compra de alimentação representa $27 \%$ do total dos gastos reconhecendo, que o sistema de produção de leite é muito exigente na alimentação. As amortizações dos equipamentos também representam 13,6\% dos gastos, justificando que isto se deve à aquisição de muitos equipamentos promovida pelos apoios governamentais e da União Europeia. Com uma menor percentagem nos custos totais estão as rendas de terrenos agrícolas e a compra de fertilizantes, com 10,6\% e 9,8\% respetivamente. Os custos salariais representam $5,6 \%$, considerando Silva (2001), que o valor da mão-de-obra é baixo devido à maioria das explorações serem do familiar. Os gastos com a conservação, reparação e fertilizantes representam em conjunto $12 \%$.

Os gastos totais para ilha de São Miguel seguem a mesma tendência que a nível regional, isto é, as amortizações contribuem com $8,9 \%$, as rendas de terras com $8,0 \%$, a alimentação com $37,3 \%$, os fertilizantes com $8,6 \%$ e os custos com os salários com 7,1\% (SILVA, 2001).

\section{Análise não paramétrica de eficiência}

A análise não paramétrica de eficiência é uma metodologia que permite avaliar a eficiência com que determinada unidade empresarial utiliza um conjunto de recursos (inputs) na produção de um conjunto de resultados (outputs). Esta avaliação é sempre relativa, porque as unidades empresariais são analisadas comparativamente a outras num conjunto de variáveis efetivamente observadas e não em relação a padrões ou standards pré-definidos.

O cálculo da eficiência económica das unidades de produção permite determinar estratégias, planeamentos e tomadas de decisões, sobretudo para as atividades com importância no desenvolvimento económico e social, como é o caso da agropecuária nos Açores. A eficiência de uma exploração é medida pela comparação entre valo- 
res observados e os valores ótimos dos seus produtos (saídas) e recursos (entradas).

Segundo Mello et al. (2005), a eficiência é um conceito relativo. Compara o que foi produzido versus os recursos disponíveis com o que poderia ter sido produzido com os mesmos recursos. Contudo, a eficiência diferencia-se da eficácia, porque a eficácia está ligada apenas ao que é produzido sem ter em conta os recursos usados para a produção, ou seja, é a capacidade da unidade produtiva atingir a produção que tinha como objetivo. Este objetivo tanto pode ter sido estabelecido pela própria unidade como externamente, dependente das expectativas de cada um.

A análise não paramétrica contabiliza claramente a mistura de entradas (inputs) e saídas (outputs). Este método pode ser utilizado para comparar um grupo de unidades de serviços, possibilitando identificar as unidades que são ineficientes podendo, inclusive medir a magnitude das ineficiências e comparar as unidades ineficientes com as eficientes permitindo, reduzir as ineficiências (MACEDO et al., 2003). Esta comparação pode ser feita em linhas gerais pela razão entre produção observada e produção potencial máxima alcançável, dados os recursos disponíveis, ou pela razão entre a quantidade mínima necessária de recursos e a quantidade efetivamente empregada, dada a quantidade de produtos gerados.

De acordo com Pereira (1995 apud MACEDO et al., 2003), a análise não paramétrica é uma técnica de pesquisa operacional que tem como base a programação linear e cujo objetivo é analisar comparativamente unidades independentes (empresas, departamentos, etc.) no que se refere ao seu desempenho operacional. Ela fornece uma medida para avaliar a eficiência relativa das unidades de tomada de decisão, os DMU's (Decision Making Unit). A ideia principal é a comparação dos outputs com os inputs. Charnes et al. (1978), referenciado Silva (2001), propôs em termos analíticos um modelo de programação fracional, cujas variáveis representam os pesos mais favoráveis para a unidade organizativa $j$.

$$
\begin{aligned}
\operatorname{Max} E_{c}= & \frac{\sum_{j=1}^{s} u_{j} Y_{j c}}{\sum_{i=1}^{m} v_{i} x_{i c}} \\
\text { S.a.: } \quad & \frac{\sum_{j=1}^{s} u_{j} y_{j k}}{\sum_{i=1}^{m} v_{i} x_{i k}} \leq 1, k=1,2, \ldots, c, \ldots, n \\
& u_{j} \geq 0, \forall j, \\
& v_{i} \geq 0, \forall i
\end{aligned}
$$

Em que: $E_{k}$, é razão de eficiência da unidade k, definida como a relação dos outputs sobre os inputs, com $\mathrm{k}=1, \ldots, \mathrm{n}$ variáveis; o $\mathrm{n}$ é o número total de unidades (DMU) que estão sendo avaliadas; $\mathrm{u}_{\mathrm{j}}$, com $\mathrm{j}=1, \ldots$, s outputs de cada variável, é o coeficiente de saída para j, onde s é o número total de tipos de saídas sendo considerados. A variável $u_{i}$ é a medida da diminuição relativa na eficiência com cada unidade de redução do valor de saída; $\mathrm{v}_{\mathrm{i}}$, com $\mathrm{i}=1, \ldots, \mathrm{m}$ inputs de cada DMU, é o coeficiente de entrada para i, onde m é o número total de tipos de entrada. A variável $v_{i}$ mede o aumento relativo na eficiência com cada redução unitária do valor de entrada; $y_{\mathrm{jk}}$ é o número observado de unidades de saída j, geradas pela unidade de serviço $k$ durante um período de tempo; $x_{\mathrm{ik}}$ é o número real de unidades de entrada $\mathrm{i}$, utilizadas pelas unidades de serviços $\mathrm{k}$ durante um período de tempo.

A mensuração dos valores para u e v, que são os pesos é determinado informaticamente pelo programa Data Envelopment Analysis Program (DEAP), atendendo à maximização da soma ponderada dos outputs dividida pela soma ponderada dos inputs da DMU em estudo, sujeita à restrição de que esse quociente seja menor ou igual a 1. Este modelo assume que todos os DMU se encontram numa escala de rendimentos constantes (CRS).

Banker et al. (1984) propuseram uma extensão do modelo anterior, atendendo às situações de rendimentos variáveis à escala, modificando o programa linear de formar a poder incorporar as restrições de convexidade ( $\mathrm{N}^{\prime} \not \mathcal{L}=1$, sendo $\mathrm{N}$ um vetor unitário). Este novo modelo passou-se 
a chamar de modelo de rendimentos variáveis à escala (VRS), obedecendo à seguinte expressão.

$$
\begin{aligned}
& \operatorname{Min}_{q \chi} q \\
& \text { s.a: } \\
& -\mathrm{y}_{\mathrm{i}}+\mathrm{Y} \mathbb{Z} \geq 0 \\
& 2 \mathrm{x}_{\mathrm{i}}-\mathrm{X} \not \mathbf{L} \geq 0 \\
& \text { N1' } \not 2=1 \\
& x \geq 0
\end{aligned}
$$

Em que: $X=$ matriz de inputs; $Y=$ matriz de outputs; $Q=$ Escalar. Vetor multiplicador aos inputs; $\not \mathcal{L}=$ Vetor de constantes $(\mathrm{Nx} 1)$ Multiplicador da matriz dos inputs e outputs.

Esta importante alteração permite dividir a eficiência técnica global em duas componentes, a eficiência técnica pura e a eficiência de escala. Para isso, deve-se calcular os dois modelos, CRS e VRS com os mesmos dados. Se existir uma diferença entre as duas medições para o mesmo DMU em particular, significa que é ineficiente em escala, sendo o valor da ineficiência calculado pela diferença entre a medição de CRS e a medição VRS.

Silva (2001) calculou a eficiência técnica para três modelos de explorações leiteiras nos Açores atendendo para o Modelo 1: output (produção de leite total); input (SAU, número de vacas e custos associados à atividade leiteira); para o Modelo 2: output (PL total e os subsídios/ha (subsídios/ha)); input (SAU, número de vacas e custos variáveis e fixos associados à atividade leiteira); e para o Modelo 3: output (PL total); input (SAU, número de vacas e custos variáveis e fixos associados à atividade leiteira). Silva (2001) concluiu que das 122 explorações estudadas, somente 7 foram eficientes, com uma média de eficiência técnica de $66,4 \%$. Os modelos 1 e 3 obtiveram iguais resultados, ambos tiveram 5 explorações eficientes e uma média de $65,2 \%$ de eficiência técnica. O modelo 2, com a introdução dos Subsídios/ha nos outputs melhorou para $66,4 \%$ a eficiência técnica e aumentou para 9 as explorações eficientes.

Arzubi et al. (2002) concluíram que em 21 explorações leiteiras de Buenos Aires (Argentina), a eficiência técnica de $83 \%$ no exercício de 1997/1998 aumentou para 87\% no exercício de 1999/2000.

De acordo com Santos et al. (2009), a eficiência técnica com os retornos constantes nas explorações da região do Rio Grande do Sul, no Brasil foi em média de 65,6\% com um desvio padrão de $21,2 \%$, utilizando o método de análise não paramétrica de eficiência.

\section{Metodologia}

Para a realização do presente trabalho, recorreu-se aos dados de 91 explorações agropecuárias da ilha de São Miguel inscritas no Contraste Leiteiro e que realizaram contabilidade organizada em 2010.

As 91 explorações leiteiras da ilha de São Miguel, estão distribuídas pelos seis concelhos, correspondendo a $37 \%$ das explorações que tiveram resultados apurados em contraste leiteiro em 2010 (SDASM-a), e b), 2011). O concelho mais representado é o da Ribeira Grande com 39 explorações, seguindo-se o de Ponta Delgada com 35 explorações. O concelho menos representado é o da Vila Franca do Campo com apenas 2 explorações.

Das 91 explorações, 53,8\% têm mais de $75 \mathrm{CN}$ e 39,6\% têm entre 30-75 CN. Somente 6 explorações $(6,6 \%)$ têm menos de 30 cabeças normais. $\mathrm{O}$ maior número de explorações com mais de $90 \mathrm{CN}$ neste estudo deve-se essencialmente, à obrigação das explorações agrícolas com faturação superior a $150.000 €$, de elaborarem contabilidade organizada, enquanto as explorações com faturação inferior a $150.000 €$ poderem optar pela contabilidade simplificada.

A maioria das explorações (51) deste estudo tem uma quota leiteira atribuída entre 251.000 e as $500.000 \mathrm{~kg}$. Observa-se, igualmente, no mesmo gráfico que 18 explorações agropecuárias têm uma quota leiteira entre 501 e 750 mil $\mathrm{kg}$ e 13 explorações uma quota inferior a 250 mil de quota leiteira. 


\section{Análise não paramétrica de eficiência (DEA)}

Os dados foram organizados numa folha em Excel, listados em colunas dos outputs, seguidos pelas colunas dos inputs. Para a obtenção dos resultados da eficiência das explorações agropecuárias utilizou-se o programa DEAP (Data Envelopment Analysis Program) (COELLI, 1996).

Para conhecer a eficiência das explorações leiteiras da ilha de São Miguel foi equacionado dois modelos:

\subsection{Modelo I}

Output: foram incluídas as variáveis da Venda de Leite por hectare (VL), Vendas Diversas por hectare (VDv) e Subsídios por hectare (Subs/ha).

Input: foram incluídos todos os custos totais ligados à atividade da exploração agropecuária, a Superfície Agrícola Útil (SAU) e o número de cabeças normais $(\mathrm{CN})$.

Neste modelo, os valores considerados nos outputs são os que representam a entrada monetária, ou seja, a venda de leite anual que as explorações produziram no ano de 2010, juntamente com as vendas diversas, como é o caso de venda de vitelos, vacas para refugo. Foi considerado os subsídios por hectare atribuídos à exploração como fator de rendimento. Aos inputs foram considerados todos os custos associados às despesas por hectare: custos de alimentação (Calim); Custos de fertilizantes (CFert); Custos de Amortização (CAmort); custos de conservação e reparação de equipamentos (CCRE); Custos de eletricidade (CElec); Imposto sobre rendimentos (IR); Custos das Rendas (CRendas); CAME; custos dos salários (CSalár); custos de veterinário (CVet) e custos diversos $(\mathrm{CDv})$, mais a SAU e o número de $\mathrm{CN}$.

\subsection{Modelo II}

Output: foram incluídas as variáveis da VL, VDv.

Input: foram incluídos todos os custos totais ligados à atividade da exploração agropecuária, o SAU e o número de $\mathrm{CN}$.
O modelo I diferencia-se do modelo II somente na incorporação dos Subsídios por hectare no output, uma vez que esta variável não deve ser considerada como fonte de rendimento e as explorações agropecuárias devem ser eficientes sem este apoio.

\section{Resultados e discussão}

No Quadro 3, a seguir, encontra-se sumariada as estatísticas descritivas das variáveis analisadas para as 91 explorações (ALMEIDA, 2012).

Verifica-se através do Quadro 3, que a média do RL das explorações analisadas no ano de 2010 foi de $1.002,93 € / h a$, um valor mais alto em relação a Silva (2001) que era de 606,56 €/ha.

Em média estas explorações deste estudo têm 2,49 CN/ha e 40,41 ha de área útil, sendo largamente superior à média das explorações da ilha de São Miguel que se situa nos 8,9 ha de SAU (SREA, 2011). Constata-se também que a média de PL305 das explorações foi de $8.061 \mathrm{~kg}$, mais 263 $\mathrm{kg}$ de leite em relação à média das explorações micaelenses em Contraste Leiteiro no mesmo ano (SDASM-a) e b), 2011). Observa-se também que o coeficiente de variação para as variáveis produtivas e morfológicas têm uma baixa dispersão deduzindo, dessa forma, alguma homogeneidade dos valores destas variáveis nas explorações do estudo.

No Quadro 3, optou-se por agrupar seis variáveis independentes nomeadamente, CElec, Custos em água (CAgua), Custos em seguros (CSeguros), custos de produtos de limpeza (CLimp), Custos de Inseminação Artificial (CIA) e CQuotas, numa única variável a que se atribui o nome de Custos Diversos (CDv). A razão para reunir estas variáveis prende-se com o facto de cada uma apresentar um valor inferior a $2 \%$ do total da percentagem dos custos associados às despesas de uma exploração.

Na Figura 1 observa-se que os custos em alimentação representam $25,32 \%$ dos custos gerais de uma exploração agropecuária, valor mais baixo ao apresentado por Silva (2001) para a ilha de São 
Quadro 3. Estatística descritiva das variáveis de dimensão, contabilísticas, produção e morfológicas

\begin{tabular}{|c|c|c|c|c|c|}
\hline Variáveis & Média & DP & $\mathrm{CV}$ & Min. & Max. \\
\hline SAU & 40,41 & 29,49 & $72,98 \%$ & 6,89 & 183,60 \\
\hline $\mathrm{CN}$ & 89,55 & 52,54 & $58,72 \%$ & 22 & 350 \\
\hline CN/ha & 2,49 & 0,80 & $32,18 \%$ & 0,92 & 5,52 \\
\hline $\mathrm{CNv}$ & 66,67 & 40,01 & $60,01 \%$ & 16 & 263 \\
\hline IR & 126,38 & 142,98 & $113,13 \%$ & $-76,70$ & 835,43 \\
\hline CAlim & 663,47 & 230,57 & $34,75 \%$ & 192,00 & 1336,04 \\
\hline CFert & 332,89 & 185,95 & $55,86 \%$ & 22,17 & 1250,69 \\
\hline CAmort & 250,39 & 264,30 & $105,55 \%$ & 0,00 & 1142,16 \\
\hline CCRE & 269,57 & 229,48 & $85,13 \%$ & 39,30 & 1657,03 \\
\hline CElec & 33,20 & 55,10 & $165,96 \%$ & 0,00 & 293,80 \\
\hline CComb & 282,92 & 170,59 & $60,30 \%$ & 33,40 & 978,00 \\
\hline CAgua & 18,40 & 34,40 & $186,95 \%$ & 0,00 & 238,50 \\
\hline CRendas & 115,47 & 106,52 & $92,25 \%$ & 0,00 & 414,77 \\
\hline CAME & 143,15 & 141,64 & $98,95 \%$ & 0,00 & 685,50 \\
\hline CSeguros & 23,22 & 22,40 & $96,46 \%$ & 0,00 & 98,20 \\
\hline CLimp & 44,71 & 36,00 & $80,51 \%$ & 0,00 & 207,89 \\
\hline CVet & 65,24 & 37,91 & $58,10 \%$ & 8,67 & 209,97 \\
\hline CIA & 19,80 & 11,30 & $57,07 \%$ & 0,11 & 53,90 \\
\hline CQuotas & 35,63 & 17,84 & $50,07 \%$ & 9,31 & 116,65 \\
\hline CSalár & 196,34 & 229,87 & $117,07 \%$ & 0,00 & 1161,05 \\
\hline VL & 3794,02 & 1952,22 & $51,46 \%$ & 986,30 & 13733,72 \\
\hline VDv & 212,88 & 232,21 & $109,08 \%$ & 0,00 & 1342,02 \\
\hline Subs/ha & 1090,06 & 423,58 & $38,86 \%$ & 90,95 & 3037,00 \\
\hline PLL & 0,265 & 0,251 & $9,46 \%$ & 0,211 & 0,352 \\
\hline RL & 1002,93 & 839,76 & $83,73 \%$ & $-810,70$ & 4460,60 \\
\hline PL305 & 8061,40 & 1188,29 & $14,74 \%$ & 5391,00 & 11256,00 \\
\hline PG305 & 288,73 & 40,97 & $14,19 \%$ & 206,00 & 400,00 \\
\hline PP305 & 262,85 & 38,99 & $14,84 \%$ & 173,00 & 382,00 \\
\hline $\mathrm{ST}$ & 80,53 & 2,61 & $3,17 \%$ & 73,00 & 89,00 \\
\hline CAP & 81,55 & 2,09 & $2,50 \%$ & 77,00 & 88,00 \\
\hline CarL & 81,50 & 1,40 & $1,73 \%$ & 77,00 & 85,00 \\
\hline $\mathrm{PP}$ & 82,19 & 1,46 & $1,67 \%$ & 77,00 & 85,00 \\
\hline SM & 80,19 & 1,84 & $2,28 \%$ & 76,00 & 84,00 \\
\hline PF & 80,89 & 1,52 & $1,79 \%$ & 78,00 & 85,00 \\
\hline
\end{tabular}

Fonte: Almeida (2012).

Miguel, que indicava 37,3\% deste custo e de 27\% para os Açores. Esta variável é, sem dúvida a que tem maior expressividade nos custos associados de uma exploração. A alimentação representa em média 19,6\% da venda de leite por hectare, havendo um máximo de $53,59 \%$ e um mínimo de $6,99 \%$ da venda de leite por hectare.

Os custos de fertilizantes representam a segunda maior percentagem na estrutura de custos, com $12,70 \%$, um valor $4,1 \%$ superior ao apresentado por Silva (2001). Também com um aumento do peso nos custos, está os custos em carburantes representando $10,79 \%$ do total da despesa das explorações leiteiras açorianas, mais 6,59\% que Silva (2001), justificado pelo aumento compulsivo do preço do combustível. A conservação e reparação de equipamento, as amortizações e os salários representam respetivamente, $10,29 \% ; 9,55 \%$ e $7,49 \%$ da estrutura total dos inputs, sendo ligeiramente diferentes em relação a Silva (2001) que apresentou percentagens de $5,2 \% ; 8,9 \%$ e $7,1 \%$, respetivamente. 
Figura 1. Estrutura dos gastos das explorações em São Miguel, em 2011

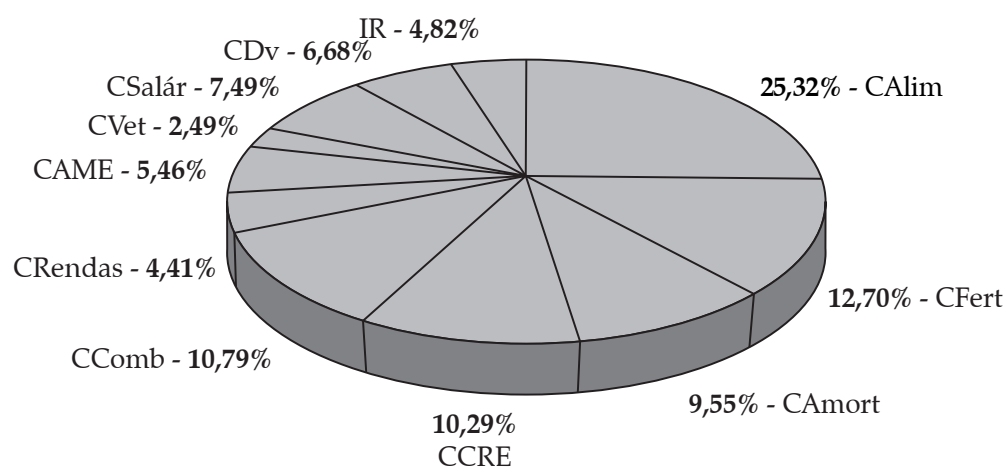

Fonte: Contunião Agrícola (2011).

Figura 2. Estrutura de proveitos das explorações em São Miguel, em 2011

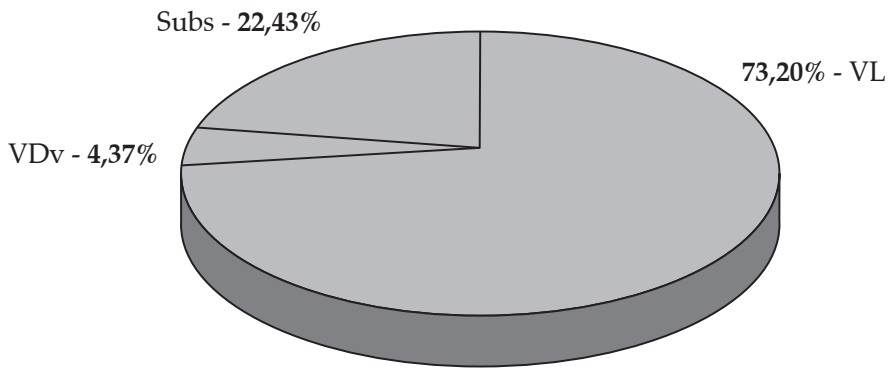

Fonte: Contunião Agrícola (2011).

Em relação aos outputs criados pelas explorações agropecuárias micaelenses, a venda de leite é, sem dúvida, a variável que mais favorece a rentabilidade líquida por hectare, representando $73,20 \%$ do total (Figura 2). Com pouca expressividade, mas não menos importante está a venda de diversos que totaliza $4,37 \%$ dos proveitos.

Os subsídios por hectare atribuídos às explorações dos Açores atingem uma média de 1.090,06€, representando $22,43 \%$ do total dos outputs que contribuem para a RL. Esta percentagem chega a representar um máximo de 37,39\% e um mínimo de $0,82 \%$. Esta variável protagoniza uma importância vital na rentabilidade das explorações em que por exemplo, a diferença entre a RL e os subsídios por hectare obtém-se uma média de $-87,13 €$, o que significa que algumas explorações micaelenses não são rentáveis sem a atribuição dos subsídios. Do total das 91 explorações desta amostra, 60,44\% das explorações têm resultados negativos sem os subsídios e somente $39,56 \%$ tem resultados positivos.

Do total dos subsídios que auferem as explorações micaelenses, 46,2\% são os apoios aos Produtos Lácteos, ou por outras palavras o subsídio da quota. A segunda maior comparticipação provém das ajudas ao prémio da vaca leiteira, representando $27,5 \%$ do total. As Indeminizações Compensatórias, o apoio às Culturas Arvenses, o subsídio ao Abate, a Extensificação e outros subsídios, representam em conjunto 26,3\% (ALMEIDA, 2012).

Com o fim anunciado das quotas leiteiras, os produtores micaelenses perdem em média 46,2\% dos subsídios/ha que lhes são atribuídos. Com este cenário perder-se-á em média 10,36\% do total de receitas, com evidente quebra na rentabilidade das explorações (ALMEIDA, 2012). 
Constata-se que as explorações deste estudo têm uma taxa média de rendimento líquido por hectare sobre o total dos proveitos, ou seja, um lucro real incluindo os subsídios/ha na ordem dos $19,80 \%$, o que significa que $80,20 \%$ são despesas. Esta percentagem desce drasticamente para níveis negativos de $-4,20 \%$ quando se retira os subsídios às explorações, atingindo níveis mínimos de $-70,60 \%$ (ALMEIDA, 2012). Num eventual panorama de não atribuição de subsídios às explorações agropecuárias deste estudo, apenas 36 explorações micaelenses conseguiriam sobreviver financeiramente, ou seja, apresentando resultados positivos, sendo que 19 destas explorações têm percentagens de rentabilidade líquida por hectare abaixo dos $10 \%$. Verifica-se que a maioria das explorações micaelenses são altamente dependentes dos subsídios que usufruem.

\section{Análise não paramétrica de eficiência}

O Quadro 4 apesenta para os modelos (I e II), os valores para a eficiência técnica com rendimentos constantes (CRSTE), para a eficiência técnica com rendimentos variáveis (VRSTE) e para a eficiência em escala (SCAL).

Para os rendimentos constantes à escala para o Modelo I verifica-se, que das 91 explorações leiteiras, apenas 7 delas obtiveram máxima eficiência técnica $\left(E_{j}=1\right)$, o que equivale a $7,69 \%$ da amostra. O nível médio de ineficiência técnica neste modelo é de $0,312(1-0,688)$, o que significa que se pode reduzir em média até 31,2\% dos gastos nos consumos, sem penalizar a produção.
Verifica-se também que a eficiência técnica baixa de $68,8 \%$ no Modelo I para $63,7 \%$ no Modelo II, com uma diminuição para 5 explorações eficientes tecnicamente, equivalente a 5,49\% da amostra, sendo que estas 5 incorporam na lista das explorações eficientes do Modelo I.

Estes valores da eficiência média são ligeiramente mais altos do que os resultados obtidos por Silva (2001) que auferiu para o Modelo II uma eficiência técnica de $65,2 \%$, com 5 explorações eficientes, equivalente a $4,13 \%$ da amostra e uma eficiência técnica de $66,4 \%$, também ligeiramente inferior para o Modelo I.

Santos et al. (2009) obtiveram, nas mesmas circunstâncias do Modelo II, resultados ligeiramente superiores para as explorações agropecuárias do Rio Grande do Sul (Brasil), atingindo uma eficiência técnica de 65,6\%. Em comparação também com o Modelo II, Arzubi et al. (2002) obtiveram resultados de $87,0 \%$ de eficiência técnica, muito superior aos $63,7 \%$ deste modelo.

Considerando os rendimentos variáveis à escala, o panorama melhora um pouco, no Modelo I existe um aumento da média de eficiência técnica para $81,5 \%$ e um aumento para 14 explorações eficientes, representando 15,38\% da amostra. Observa-se ainda que as explorações no Modelo II diminuíram a eficiência média para $78,5 \%$, verificando uma redução de 2 explorações eficientes em relação ao modelo com a inclusão dos subsídios/ha.

No Quadro 5 estão representados os dados estatísticos das explorações eficientes tecnicamente para ambos os modelos. Regista-se que a Pontuação Final (PF) tem os mesmos valores e

Quadro 4. Dados estatísticos estimados para o Modelo I e Modelo II

\begin{tabular}{l|ccc|ccc}
\hline & \multicolumn{3}{|c|}{ Modelo I } & \multicolumn{3}{c}{ Modelo II } \\
\cline { 2 - 7 } & CRSTE & VRSTE & SCAL & CRSTE & VRSTE & SCAL \\
\hline Média & 0,688 & 0,815 & 0,846 & 0,637 & 0,785 & 0,813 \\
Desvio Padrão & 0,132 & 0,120 & 0,102 & 0,126 & 0,128 & 0,101 \\
Máximo & 1 & 1 & 1 & 1 & 1 & 1 \\
Mínimo & 0,448 & 0,548 & 0,626 & 0,432 & 0,459 & 0,602 \\
Expl. Eficientes & 7 & 14 & 7 & 5 & 12 & 5 \\
\hline
\end{tabular}

Fonte: Elaboração própria. 
Quadro 5. Dados estatísticos das explorações eficientes em ambos os modelos

\begin{tabular}{c|cccc|cccc}
\hline & \multicolumn{4}{|c|}{ Modelo I (N=7) } & \multicolumn{4}{c}{ Modelo II (N=5) } \\
\cline { 2 - 8 } & Média & DP & Min & Max & Média & DP & Min & Max \\
\hline SAU & 55,1 & 64,7 & 6,9 & 183,6 & 30,7 & 37,3 & 6,9 & 95,8 \\
CN & 95,0 & 115,1 & 22,0 & 350,0 & 52,1 & 30,2 & 22,0 & 100,2 \\
RL & $1.534,9$ & $1.224,8$ & 462,8 & $3.317,8$ & $1.839,8$ & $1.340,1$ & 462,8 & $3.317,8$ \\
PL305 & $7.884,9$ & $1.224,8$ & $5.790,0$ & $9.149,0$ & $8.242,8$ & $1.006,0$ & $6.914,0$ & $9.149,0$ \\
PF & 80,7 & 1,3 & 79,3 & 82,4 & 80,7 & 1,4 & 79,3 & 82,4 \\
\hline
\end{tabular}

Fonte: Elaboração própria.

que a PL305 apresenta uma diferença de 7.884,9 $\mathrm{kg}$ para $8.242,8 \mathrm{~kg}$ de leite nos Modelos I e II. Com menos 2 explorações eficientes, o Modelo II tem uma média de RL superior ao Modelo I, não obstante de não utilizar os subsídios/ha nos outputs.

Verifica-se ainda que as explorações com CRSTE igual a 1 no Modelo I têm uma média de SAU 55,1 ha, face às explorações do Modelo II com uma média de 30,7 ha. De igual modo, as CN por exploração são de 95,0 e 52,1 para os Modelos I e II, respetivamente.

Na Figura 3 observa-se que as explorações estão maioritariamente distribuídas entre os 79 pontos e os 82 pontos de PF. As explorações com as melhores $\mathrm{CM}$, isto é, com PF superior a 84 pontos têm uma eficiência técnica entre os 0,64 e os 0,73 . As explorações com eficiência $\left(E_{j}=1\right)$ variam entre os 79 pontos e os 82 pontos de PF, significando que as explorações com melhores PF não são as que têm melhor eficiência técnica. Observa-se, igualmente, uma predominância das explorações do Modelo I (preto), com eficiência técnica maior que o Modelo II (cinza).

As explorações da amostra encontram-se distribuídas maioritariamente entre as produções de $6.500 \mathrm{~kg}$ e os $9.500 \mathrm{~kg}$ (Figura 4). Observa-se que as explorações com maiores produções de leite não são as mais eficientes tecnicamente, o que significa que estão a usar demasiados inputs para a produção conseguida. As 7 explorações com $E_{j}=1$ estão distribuídas entre os $5.790 \mathrm{~kg}$ e os $9.149 \mathrm{~kg}$ de leite aos 305 dias.

Figura 3. A Pontuação Final (PF) e a eficiência técnica das explorações leiteiras de São Miguel

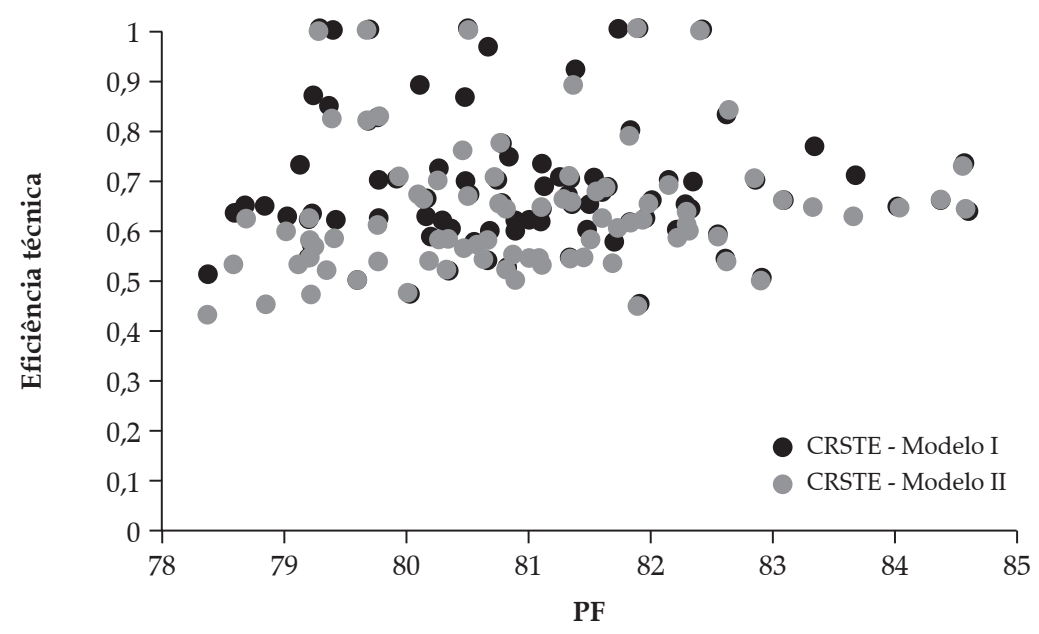

Fonte: Elaboração própria. 
Figura 4. A Produção de Leite ajustada aos 305 dias (PL305) e a Eficiência Técnica das Explorações Leiteiras de São Miguel

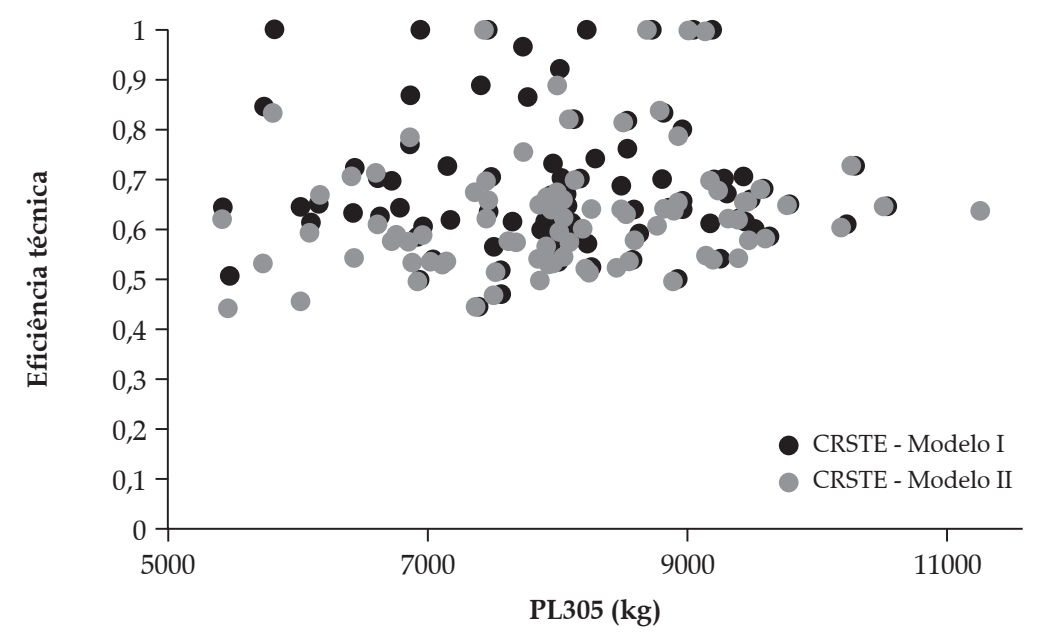

Fonte: Elaboração própria.

Conforme se verifica na Figura 5 a Rentabilidade Líquida por hectare (RL) das explorações da amostra estão maioritariamente entre os 0 e 2.000€/ ha. Observa-se que as duas explorações com maior RL têm uma eficiência técnica um pouco acima dos $60 \%$, e que as explorações com $E_{j}=1$ (ou seja, as eficientes) variam entre $462,8 €$ e os $3.317,8 €$. Constata-se que as explorações com RL maior não são obrigatoriamente as explorações mais eficientes e vice-versa. Porém, as explorações do Modelo I (pontos azuis) têm tendencialmente uma eficiência técnica maior que as explorações do Modelo II.

Figura 5. RL e a eficiência técnica das explorações de São Miguel

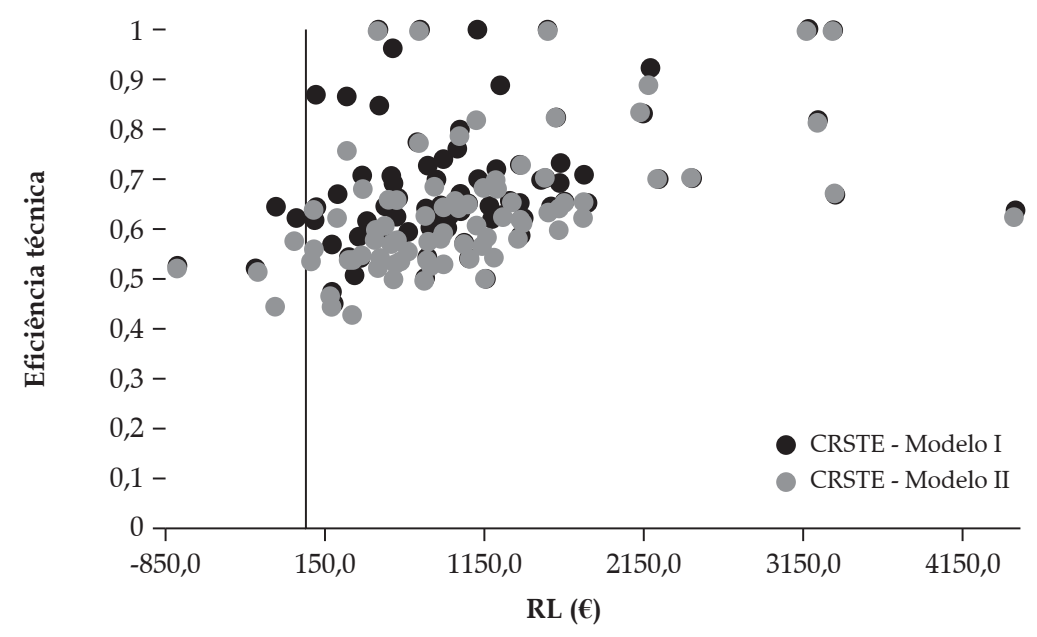

Fonte: Elaboração própria. 


\section{Conclusão}

O presente trabalho teve por objetivo conhecer a realidade das explorações agropecuárias da ilha de São Miguel, e ao mesmo tempo criar um modelo para os produtores melhorarem a rentabilidade líquida por hectare das suas empresas.

Nos resultados da análise não paramétrica de eficiência verificou-se, que as explorações leiteiras necessitam de melhorar a sua eficiência técnica, uma vez que estão a utilizar os seus recursos muito abaixo das reais possibilidades, ou seja, para se tornarem mais eficientes terão que reduzir os recursos, mantendo constantes os produtos, isto é, orientando os inputs ou o inverso, aumentando os produtos em função dos mesmos recursos utilizados. Apenas 7,69\% da amostra obteve eficiência técnica, baixando para 5,49\% da amostra quando se retira os subsídios como fonte de rendimento. Estes resultados não divergem dos resultados obtidos na década de 90 por Silva (2001), e só confirmam, mais uma vez, a elevada dificuldade das explorações leiteiras micaelenses em tornarem-se eficientes ao longo destes anos. Constatou-se também que não é possível caraterizar uma exploração eficiente, porque encontram-se com médias de pontuação final, a produção de leite aos 305 dias e a rentabilidade líquida por hectare muito diversificadas.

\section{Referências bibliográficas}

ALMEIDA, B. Modelo de Rentabilidade das Explorações Leiteiras em S. Miguel: Influência dos Fatores de Produção, da Classificação Morfológica e da Produção Leiteira dos Bovinos Leiteiros. Dissertação (Mestrado em Zootecnia), departamento de Ciências Agrárias, Universidade dos Açores, 2012.

ARZUBI, A. e BERBEL, J. Determinación de índices de eficiência mediante DEA en explotaciones lecheras de Buenos Aires. Investigación Agraria. Producción y sanidade animales, v. 17, n. 1-2, p. 103-124, 2002.

COELLI, T. A guide to DEAP version 2.1. A data envelopment analysis computer program. Centre for efficiency and productivity analysis, Department of econometrics, University of new England, Australia, 1996.
IFAP. Instituto de Financiamento da Agricultura e Pescas, 2012. Disponível em: <http://www.ifap.minagricultura.pt/portal/page/portal/ifap_publico/GC_ quotleite >. Acesso em: 10 set. 2012.

INE. Instituto Nacional de Estatística. Estatísticas Agrícolas 1999, 2000. Disponível em: <http://www.ine. pt/>. Acesso em: 17 set. 2011

Estatísticas Agrícolas 2000, 2001. Disponível em: $<$ http://www.ine.pt/>. Acesso em: 17 set. 2011.

. Estatísticas Agrícolas 2001, 2002. Disponível em: <http://www.ine.pt/>. Acesso em: 17 set. 2011.

. Estatísticas Agrícolas 2002, 2003. Disponível em: <http://www.ine.pt/>. Acesso em: 17 set. 2011.

. Estatísticas Agrícolas 2003, 2004. Disponível em: <http://www.ine.pt/> acesso em: 17/09/2011.

. Estatísticas Agrícolas 2004, 2005. Disponível em: $<$ http://www.ine.pt/>. Acesso em: 17 set. 2011.

. Estatísticas Agrícolas 2005, 2006. Disponível em: <http://www.ine.pt/>. Acesso em: 17 set. 2011.

. Estatísticas Agrícolas 2006, 2007. Disponível em: <http://www.ine.pt/>. Acesso em: 17 set. 2011.

. Estatísticas Agrícolas 2007, 2008. Disponível em: <http://www.ine.pt/>. Acesso em: 17 set. 2011.

. Estatísticas Agrícolas 2008, 2009. Disponível em: $<$ http://www.ine.pt/>. Acesso em: 17 set. 2011 e 05 mar. 2012.

. Estatísticas Agrícolas 2009, 2010. Disponível em: <http://www.ine.pt/>. Acesso em: 17 set. 2011.

Recenseamento Agrícola 2009, 2011. Análise dos principais resultados. Edição 2011. Disponível em: < http:// www.ine.pt/> . Acesso em: 17 set. 2011 e 05 mar. 2012.

MACEDO, M. e BENGIO, M. Avaliação de Eficiência Organizacional através de Análise Envoltória de Dados. VIII Congreso Internacional de Costos. 26 a 28 de nov. de 2003. Punta del Este (Uruguai), 2003.

MELLO, J. et al. Curso de Análise de Envoltória de Dados. XXXVII Simposio Brasileiro de Pesquisa Operacional. 27 a 30 set. 2005. Gramado, RS, p. 25202547, 2005.

PORTARIA no 1066/91 de 22 de Outubro. Regulamento do Contraste Leiteiro da Espécie Bovina, 1991.

SANTOS, C. e FERNANDES, R. Eficiência Técnica no Setor Agropecuário das Microregiões do Rio Grande do Sul. 47ํㅡㄹ Congresso da Sociedade Brasileira de Economia, Administração e Sociologia Rural. Porto Alegre, 26 a 30 de Julho de 2009. Livro Abstrato, 1-15, 2009. 
SDASM Contraste Leiteiro 2010. Eds. Serviço de Desenvolvimento Agrário de São Miguel, 2011a.

SDASM Contraste Leiteiro 2010. Eds. Serviço de Desenvolvimento Agrário de São Miguel, 2011b.

SILVA, E. Análisis multicritério de la eficiência económica de las explotaciones agroganaderas de las Azores (Portugal),
Tesis Doctoral, Escuela Técnica Superior de Ingenieros Agrónomos y de Montes, Universidad de Córdoba, 2001.

SREA Serviço Regional de Estatística dos Açores. Recenseamento Agrícola 2009, 2011. Disponível em: <http://www.estatistica.azores.gov.pt>. Acesso em: 27 jul. 2012. 